\title{
Original
}

\section{Re-evaluation of Peroxide Value as an Indicator of the Quality of Edible Oils}

(Received December 18, 2006)

\author{
Satoshi Shiozawa*, Masaharu Tanaka, Katsutoshi Ohno, \\ Yasuhiro NAGAO and Toshihiro YAMADA
}

Food Safety Research Institute, Nissin Food Products Co., Ltd.: 2247, Noji-cho, Kusatsu, Shiga 525-0055, Japan; *Corresponding author

\begin{abstract}
The oxidation of oils has important effects on the quality of oily foods, such as instant noodles. In particular, the generation of aldehydes, which accompanies the oxidation of oils, is one of the first factors to reduce food quality. We examined various indicators of oil quality during temperature-accelerated storage and found that peroxide value (POV) was highly correlated with the total concentration of major odorants. Moreover, the correlation of POV with the total concentration of five unsaturated aldehydes ( $t$-2-heptenal, $t$-2-octenal, $t$-2-decenal, $t$-2-undecenal and $t$,t-2,4-decadienal) that show strong cytotoxicity was greater than the correlation of POV with the total concentration of major odorants. The maximum allowable concentration of the five aldehydes was calculated based on the 'no observed adverse-effect level' of the aldehyde that showed the highest cytotoxicity, $t, t$-2,4-decadienal, along with the human daily oil intake. We showed that it is useful to utilize POV as an indicator to control food quality and safety.
\end{abstract}

Key words: acid value; aldehyde; carbonyl value; cytotoxicity; instant noodle; odorant; peroxide value; quality control

\section{Introduction}

Edible oils are autoxidized in air and generate hydroperoxide as a primary product, the subsequent reactions of which generate various secondary products, including polymers, aldehydes and ketones. By contrast, carboxylic acids are mainly generated by hydrolysis. Among the secondary products, the amounts of aldehydes and ketones increase then decrease gradually as a result of degradation, while the amounts of carboxylic acids increase due to hydrolysis in a timedependent manner. The off-flavors and toxicities of oxidized oils are caused by these secondary products ${ }^{1}$.

Foods with high oil content, such as instant noodles, suffer a remarkable decrease in quality due to oil oxidation. In Japan, a food-poisoning incident that was attributed to oil oxidation in instant noodles occurred in $1964^{2)}$. Consequently, the Ministry of Health and Welfare (currently the Ministry of Health Labor and Welfare) passed the Food Sanitation Law, which set the standard peroxide value (POV, $\leqq 30 \mathrm{meq} / \mathrm{kg}$ ) and acid value ( $\mathrm{AV}, \leqq 3 \mathrm{mg} / \mathrm{g}$ ) for oils extracted from fried-type instant noodles. These values were based on the results of research into the degradation of oils in the instant noodles involved in the 1964 incident. No similar episodes have been reported in Japan since the Food Sanitation Law came into force.

Aldehyde-induced off-flavors can be sensed by humans at low levels, and consumers will reject products at a relatively early stage of the oil oxidation process $^{3)}$. Sensory tests are therefore important in setting standards for oil oxidation. However, it would be difficult to train taste panels to perform daily quality control tests of fried food products marketed throughout the world.

Direct measurements using headspace analysis have shown a strong correlation between levels of aldehydes and odorants ${ }^{4)}$. However, this method requires expensive equipment and the odorants measured are volatiles that are present in small amounts. This technique is not suitable for measuring the low-volatility toxic aldehydes generated by oxidized oils. Hence, there is a need for a cheap and efficient method of analyzing the toxic aldehydes generated during the early stages of oil oxidation, in order to ensure the quality of oil-rich foods. In this study, we examined storage tests to find an index that has a high correlation with the concentration of odorants as an objective and comparative index that can take the place of sensory tests in quality control of food. Room temperature, which is the general storage condition of instant noodles, is suitable for this test, but we selected an accelerated shelf life test often adopted for the quality control of food to shorten the test period. We examined the correlation between various parameters, such as the carbonyl value (CV), AV and POV, and the aldehyde concentration, in order to re-evaluate the standards for the quality control of foods with high oil contents. We confimed that POV is adequate as a parameter of oil deterioration and as an indicator of food safety. 


\section{Materials and Methods}

\section{Oil samples}

Purified palm oil, lard and soybean oil (all >99.9\%) were provided by Ueda Oils and Fats Mfg Co., Ltd. (Kobe, Japan). We added extra-pure grade $( \pm)-\alpha$ tocopherol (Wako Pure Chemical Industries Co., Ltd., Kyoto, Japan) to both the palm oil and lard in order to make the total tocopherol concentration equivalent to that in soybean oil. The concentration of tocopherol in each sample was adjusted to within $1,380 \pm 20 \mu \mathrm{g} / \mathrm{g}$.

After collecting each sample into a Petri dish, the samples were covered and heated at constant temperature. Storage conditions were as follows: $90^{\circ} \mathrm{C}$ with samples taken at $1,2,3,4$ and 5 days; $70^{\circ} \mathrm{C}$ with samples taken at $4,8,12,17^{* 1}$ and 20 days; and $50^{\circ} \mathrm{C}$ with samples taken at $16,32,48,64$ and $79^{*}$ days. It is generally considered that the reaction rate doubles with every $10^{\circ} \mathrm{C}$ increase of temperature.

\section{Standard odorants}

Extra-pure grade cyclohexanol, 1-pentanol and hexanoic acid were purchased from Wako Pure Chemical Industries Co., Ltd. Pentanoic acid and 1-hexanal were purchased from Kanto Chemical Co., Ltd. (Tokyo, Japan). 1-Pentanal, 1-heptanal, t-2-heptenal, 1-octanal, $t$-2-octenal, 1-nonanal and 1-decanal were purchased from Tokyo Kasei Kogyo Co., Ltd. (Tokyo, Japan). $t$-2Decenal, $t, t$-2,4-decadienal and $t$-2-undecenal were also purchased from Tokyo Kasei Kogyo Co., Ltd.

\section{Cell lines}

Human epitheloid carcinoma cell line (HeLa), human breast cancer cell line (MCF-7), Chinese hamster lung cell line (CHL/IU) and Chinese hamster ovary cell line (CHO-KI) cells derived from the American Type Culture Collection (ATCC) were purchased from Dainippon Pharmaceutical Co., Ltd. (Osaka, Japan). Each cell type was cultured under the conditions recommended by the ATCC.

\section{Standard methods for the analysis of fats, oils and related materials}

$\mathrm{AV}$ and POV were measured as described in the Standard Methods for the Analysis of Fats, Oils and Related Materials established by the Japan Oil Chemists' Society. CV was measured by a modified method in which benzene was not used ${ }^{5)}$.

\section{Concentration of odorants}

The concentrations of odorants were determined by gas chromatography/mass spectrometry (GC/MS). Each oil sample $(10.0 \mathrm{mg})$ was diluted by adding $1 \mathrm{~mL}$ of $0.2 \mathrm{ppm}$ cyclohexanol in acetone as an internal standard $^{6)}$. The GC/MS conditions were as follows: equipment, JMS-SUN 200 (JEOL Ltd., Tokyo, Japan)

*1 The intervals ending on the collection dates marked with an asterisk differ from the others. and HP6890 (Agilent Technologies Japan, Ltd., Tokyo, Japan); column, SPB-1 SULFUR (SUPELCO, $0.32 \mathrm{~mm}$ i.d. $\times 30 \mathrm{~m}, 4 \mu \mathrm{m})$; oven temperature, isothermal for $1.5 \mathrm{~min}$ at $40^{\circ} \mathrm{C}$, increased at a rate of $20^{\circ} \mathrm{C} / \mathrm{min}$ to $160^{\circ} \mathrm{C}$, increased at a rate of $25^{\circ} \mathrm{C} / \mathrm{min}$ to $250^{\circ} \mathrm{C}$ and then isothermal for $4 \mathrm{~min}$; injection port temperature, $250^{\circ} \mathrm{C}$; injection volume, $1 \mu \mathrm{L}$ (splitless); purge time, $1 \mathrm{~min}$; carrier gas, helium $(3.0 \mathrm{~mL} / \mathrm{min})$; ionization method, electron ionization (EI); ion source temperature, $230^{\circ} \mathrm{C}$; interface temperature, $250^{\circ} \mathrm{C}$; ionization current, 300 $\mu \mathrm{A}$; ionization energy, $70 \mathrm{eV}$; and mode of acquisition, selected ion monitoring (SIM). The limit of quantitation for each of the odorants was calculated as 10 times the standard deviation; using $2.5 \mathrm{ppm}$ standard solutions, the limits of quantitation ranged from 3.0 to $5.0 \mathrm{ppm}$. The sum of the levels of the 14 compounds (1pentanal, 1-pentanol, 1-hexanal, pentanoic acid, 1heptanal, $t$-2-heptenal, hexanoic acid, 1-octanal, $t$-2-octenal, 1-nonanal, 1-decanal, $t$-2-decenal, $t, t$-2,4-decadienal and $t$-2-undecenal) was defined as the total concentration of the odorants.

\section{Cytotoxicity}

The cytotoxicity test was carried out according to the method described by Kimoto et $a l_{.}{ }^{7)}$, after preparing ethanol emulsions of the oil samples. Using the wellestablished liposome method, liposomes did not form up to the maximum concentration of the oil $(0.3 \mathrm{mg} / \mathrm{mL})$; thus, each sample was suspended in ethanol to achieve higher concentrations. An ethanol suspension was prepared for each sample $(200 \mathrm{mg} / \mathrm{mL})$ and a $0.05 \mathrm{~mL}$ sample was added to $0.95 \mathrm{~mL}$ of culture medium. After vortexing, the suspension was diluted with an equal volume of medium and subjected to cytotoxicity testing (final ethanol concentration $<2 \%$ ). Solid palm oil and lard did not disperse in the medium at room temperature using this method; thus, only soybean oil was subjected to the cytotoxicity test. For fatty acids and related materials with off-flavors, the individual compounds were dissolved in ethanol and added to the medium at a final ethanol concentration of $1 \%$.

Cytotoxicity testing was carried out using four cell lines - two Chinese hamster cell lines (CHL/IU and CHO-KI) and two human cell lines (HeLa and MCF-7) which are commonly used in standard cytotoxicity tests. ${ }^{8)}$ The cells were plated in 96-well microplates (FALCON, Bedford, MA) at a concentration of 2,000 cells/well and incubated overnight at $37^{\circ} \mathrm{C}$ under $5 \%$ $\mathrm{CO}_{2}$. After removal of the medium, $100 \mu \mathrm{L}$ of fresh medium containing the test sample was added to each well and the plate was incubated at $37^{\circ} \mathrm{C}$ under $5 \% \mathrm{CO}_{2}$ for $48 \mathrm{~h}$ (triplicate assay). The medium was replaced, and the cytotoxicity was evaluated using the PreMix WST-1 cell-proliferation assay system (TaKaRa Bio Inc., Shiga, Japan). This assay uses a modified version of the MTT method, which is based on the cleavage of the water-soluble tetrazolium salt WST-1 to formazan by cellular mitochondrial dehydrogenases ${ }^{9)}$. Moreover, it is a cell proliferation assay, rather than staining dead 
(A)

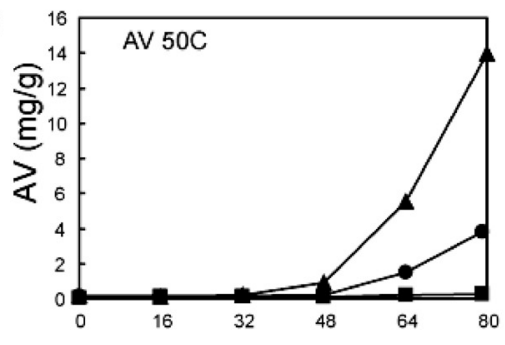

(B)

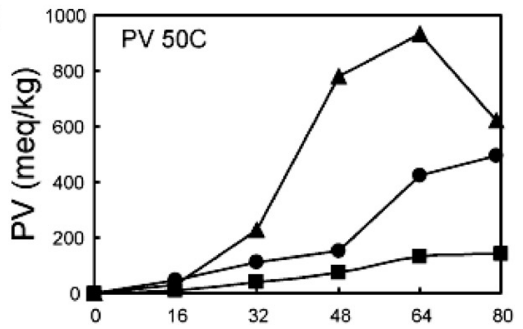

(C)

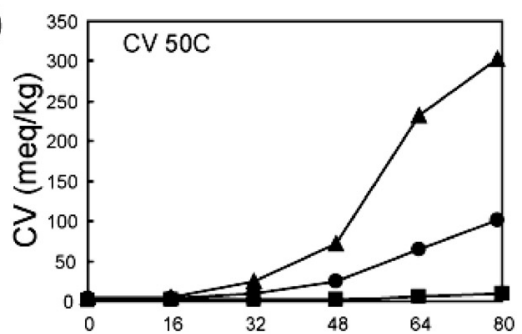

(D)

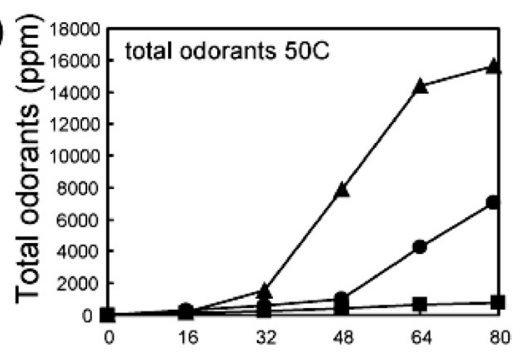

(E)

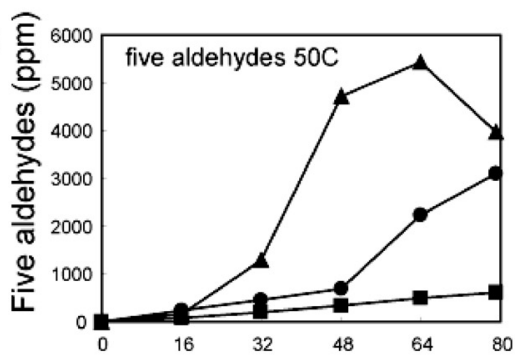

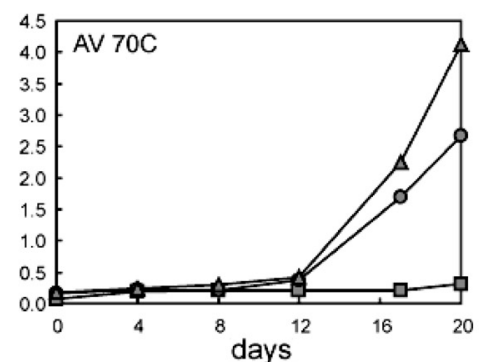
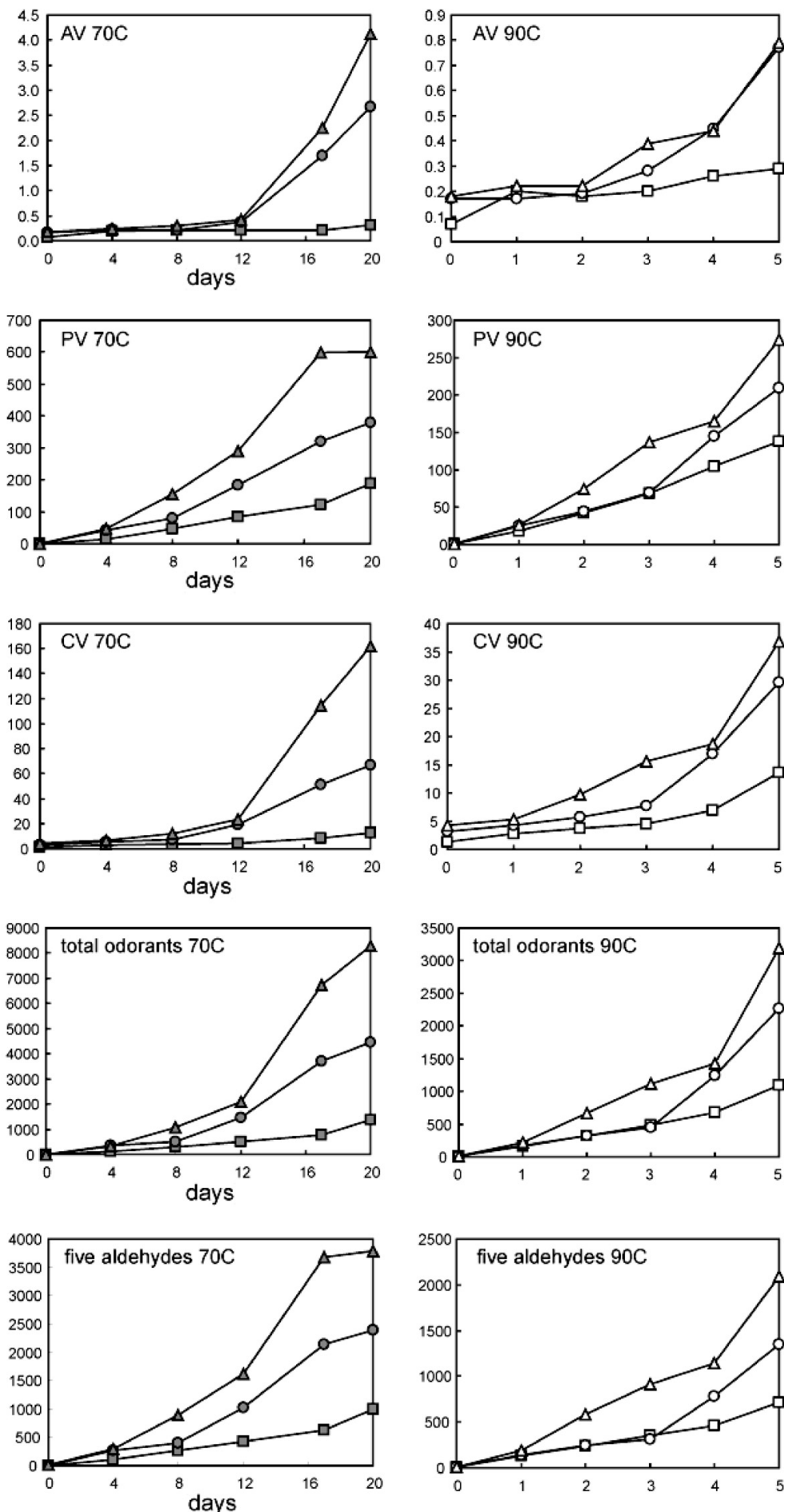

$50^{\circ} \mathrm{C}$ palm oil $(\longrightarrow-), 50^{\circ} \mathrm{C}$ lard $(\longrightarrow), 50^{\circ} \mathrm{C}$ soybean oil $(\longrightarrow-)$,

$70^{\circ} \mathrm{C}$ palm oil $\left(-\square-70^{\circ} \mathrm{C}\right.$ lard $(\neg-), 70^{\circ} \mathrm{C}$ soybean oil $(\square-)$,

$90^{\circ} \mathrm{C}$ palm oil $(-\square-), 90^{\circ} \mathrm{C}$ lard $(-0-), 90^{\circ} \mathrm{C}$ soybean oil $(\neg-)$.

Fig. 1. Changes in AV, POV, CV and the concentrations of total odorants and five aldehydes ( $t$-2-heptenal, $t$-2-octenal, $t$-2decenal, $t, t$-2,4-decadienal and $t$-2-undecenal) under three storage conditions

In each graph, the scale on the ordinate axis was adjusted so as to locate the maximum value near to the top. 
cells. A sample $(10 \mu \mathrm{L})$ of WST-1 solution was added to each well and incubated at $37^{\circ} \mathrm{C}$ for $1 \mathrm{~h}$. The absorbance at $450 \mathrm{~nm}$ with a $655 \mathrm{~nm}$ reference wavelength was then measured using a microplate reader (Model 3550; Bio-Rad Laboratories, Hercules, CA), and the number of viable cells was determined based on the obtained absorbance in a triplicate assay. The half-maximal inhibitory concentration $\left(\mathrm{IC}_{50}\right)$ values for cell proliferation were calculated using the Probit method.

\section{Statistical analysis}

Linear regression analysis was carried out using Microsoft Excel 2000 version 9.0 software, and the coefficients of determination $\left(r^{2}\right)$ and probabilities $(p$ value) were calculated.

\section{Results and Discussion}

\section{Changes in the concentration of total odorants}

At $50^{\circ} \mathrm{C}$, the concentration of odorants in soybean oil increased in a time-dependent manner after the $32 \mathrm{nd}$ day, and that in lard increased in the same manner after the 48th day (Fig. $1(\mathrm{~A})$ ). At $70^{\circ} \mathrm{C}$, the concentration of odorants in soybean oil and lard increased in a timedependent manner after the 8th day for soybean oil and the 12 th day for lard. The results at $90^{\circ} \mathrm{C}$ did not match the changes in the sum of the concentrations of odorants observed at $50^{\circ} \mathrm{C}$, indicating $90^{\circ} \mathrm{C}$ is not suitable for accelerated shelf life testing.

\section{Cytotoxicity of oxidized soybean oil and odorants to mam-} malian cell lines

Table 1 shows the cytotoxicity of 14 compounds that were detected as odorants in this study, as well as two soybean oil samples. Saturated alcohol and saturated carboxylic acids did not show high cytotoxicity, al- though pentanoic acid showed weak cytotoxicity in HeLa and CHO-KI cells. Among the six saturated aldehydes, compounds with longer carbon chains tended to have higher cytotoxicity, although the values were not particularly high. By contrast, the $\mathrm{IC}_{50}$ values of all five unsaturated aldehydes were reached at concentrations below $20 \mu \mathrm{g} / \mathrm{mL}$, with $t, t-2,4$-decadienal showing the highest cytotoxicity. The toxicity data for these unsaturated aldehydes were in good agreement with those reported previously ${ }^{10)}$.

The concentration of $t, t-2,4$-decadienal in soybean oil that had been incubated at $90^{\circ} \mathrm{C}$ for 5 days was $1,449.1$ ppm. Assuming that the cytotoxicity of the sample was due to $t, t$-2,4-decadienal alone, its concentration was estimated as $1,691.7 \mathrm{ppm}\left(1.8 / 1,064 \times 10^{6}\right)$ based on the $\mathrm{IC}_{50}$ values of $t, t-2,4$-decadienal and the sample towards HeLa cells (1.8 and $1,064 \mu \mathrm{g} / \mathrm{mL}$, respectively). The estimated value was about $117 \%$ of the actual concentration detected in the sample, suggesting that the cytotoxicity of the oxidized oils was mainly due to unsaturated aldehydes (such as $t, t-2,4$-decadienal). The changes in the sum of the concentration of the five unsaturated aldehydes are shown in Fig. 1(B).

\section{Statistical analysis}

We investigated the correlations between the concentration of total odorants or five unsaturated aldehydes and $\mathrm{AV}, \mathrm{POV}$ and $\mathrm{CV}$ under three storage conditions. AV was not highly correlated with the concentration of total odorants or the five aldehydes (Table 2). POV showed significant correlations with the concentrations of total odorants and the five aldehydes. In particular, the changes in the concentration of the five aldehydes were similar to those of POV (Fig. 1(C) and 1(E)). CV was also highly correlated with the concentrations of total

Table 1. Cytotoxic effects of oils and related compounds

\begin{tabular}{|c|c|c|c|c|c|}
\hline \multirow{2}{*}{ Sample type } & \multirow{2}{*}{ Sample name } & \multicolumn{4}{|c|}{$\mathrm{IC}_{50}$ values of cell survival $(\mu \mathrm{g} / \mathrm{mL})^{*}$} \\
\hline & & $\mathrm{HeLa}$ & MCF-7 & CHL/IU & $\mathrm{CHO}-\mathrm{KI}$ \\
\hline Saturated alcohol & 1-Pentanol & $>1,000$ & $>1,000$ & $>1,000$ & $>1,000$ \\
\hline \multirow[t]{2}{*}{ Saturated carboxylic acids } & Pentanoic acid & 161 & $>1,000$ & $>1,000$ & 412 \\
\hline & Hexanoic acid & 966 & 687 & $>1,000$ & $>1,000$ \\
\hline \multirow[t]{6}{*}{ Saturated aldehydes } & 1-Pentanal & $>1,000$ & $>1,000$ & $>1,000$ & $>1,000$ \\
\hline & 1-Hexanal & 424 & 329 & 485 & 416 \\
\hline & 1-Heptanal & 503 & 443 & 502 & 526 \\
\hline & 1-Octanal & 176 & 146 & 154 & 161 \\
\hline & 1-Nonanal & 99.7 & 125 & 76.4 & 59.2 \\
\hline & 1-Decanal & 44.0 & 61.2 & 47.0 & 30.7 \\
\hline \multirow[t]{5}{*}{ Unsaturated aldehydes } & $t$-2-Heptenal & 3.1 & 7.5 & 2.6 & 2.6 \\
\hline & $t$-2-Octenal & 16.9 & 19.3 & 8.0 & 6.7 \\
\hline & $t$-2-Decenal & 4.2 & 9.2 & 9.0 & 5.3 \\
\hline & $t$-2-Undecenal & 4.7 & 16.7 & 15.4 & 5.2 \\
\hline & $t, t-2,4$-Decadienal & 1.8 & 1.7 & 3.2 & 1.1 \\
\hline \multirow[t]{3}{*}{ Soybean oils** } & Non-treated & $>5,000$ & $>5,000$ & $>5,000$ & $>5,000$ \\
\hline & $90^{\circ} \mathrm{C}$ for 2 days & 3,279 & $>5,000$ & $>5,000$ & 1,808 \\
\hline & $90^{\circ} \mathrm{C}$ for 5 days & 1,064 & 1,966 & 1,783 & 807 \\
\hline
\end{tabular}

* The cytotoxicities of samples in various cell lines are indicated in terms of the $\mathrm{IC}_{50}$ values (that is, the half-maximal inhibitory concentration for cell survival).

** Treated soybean oils were continuously exposed to heat $\left(90^{\circ} \mathrm{C}\right.$ for 2 or 5 days). 
Table 2. Linear correlation coefficients of the concentrations of total odorants and five unsaturated aldehydes with AV, $\mathrm{POV}$ and $\mathrm{CV}$ under three storage conditions

\begin{tabular}{|c|c|c|c|c|c|c|}
\hline & \multirow{2}{*}{ Temperature } & \multirow{2}{*}{ Sample } & \multicolumn{2}{|c|}{ vs. total odorants } & \multicolumn{2}{|c|}{$\begin{array}{l}v s . \text { five unsaturated } \\
\text { aldehydes }\end{array}$} \\
\hline & & & $r^{2}$ & $p$ value & $r^{2}$ & $p$ value \\
\hline \multirow{9}{*}{ AV } & \multirow{3}{*}{$50^{\circ} \mathrm{C}$} & Palm oil & 0.7265 & 0.0311 & 0.7055 & 0.0364 \\
\hline & & Lard & 0.9528 & 0.0009 & 0.8914 & 0.0046 \\
\hline & & Soybean oil & 0.7169 & 0.0335 & 0.2866 & 0.2737 \\
\hline & \multirow{3}{*}{$70^{\circ} \mathrm{C}$} & Palm oil & 0.8341 & 0.0110 & 0.8266 & 0.0120 \\
\hline & & Lard & 0.9364 & 0.0016 & 0.8862 & 0.0051 \\
\hline & & Soybean oil & 0.9232 & 0.0023 & 0.8078 & 0.0149 \\
\hline & \multirow{3}{*}{$90^{\circ} \mathrm{C}$} & Palm oil & 0.8646 & 0.0072 & 0.8721 & 0.0064 \\
\hline & & Lard & 0.9868 & 0.0001 & 0.9788 & 0.0002 \\
\hline & & Soybean oil & 0.9782 & 0.0002 & 0.9514 & 0.0009 \\
\hline \multirow{9}{*}{ POV } & \multirow{3}{*}{$50^{\circ} \mathrm{C}$} & Palm oil & 0.9845 & 0.0001 & 0.9828 & 0.0001 \\
\hline & & Lard & 0.9411 & 0.0013 & 0.9838 & 0.0001 \\
\hline & & Soybean oil & 0.7704 & 0.0215 & 0.9967 & 0.0000 \\
\hline & \multirow{3}{*}{$70^{\circ} \mathrm{C}$} & Palm oil & 0.9884 & 0.0001 & 0.9980 & 0.0000 \\
\hline & & Lard & 0.9785 & 0.0002 & 0.9930 & 0.0000 \\
\hline & & Soybean oil & 0.9505 & 0.0009 & 0.9975 & 0.0000 \\
\hline & \multirow{3}{*}{$90^{\circ} \mathrm{C}$} & Palm oil & 0.9801 & 0.0001 & 0.9810 & 0.0001 \\
\hline & & Lard & 0.9717 & 0.0003 & 0.9818 & 0.0001 \\
\hline & & Soybean oil & 0.9626 & 0.0005 & 0.9928 & 0.0000 \\
\hline \multirow{9}{*}{$\mathrm{CV}$} & \multirow{3}{*}{$50^{\circ} \mathrm{C}$} & Palm oil & 0.8570 & 0.0081 & 0.8368 & 0.0106 \\
\hline & & Lard & 0.9890 & 0.0000 & 0.9863 & 0.0001 \\
\hline & & Soybean oil & 0.9408 & 0.0013 & 0.5769 & 0.0798 \\
\hline & \multirow{3}{*}{$70^{\circ} \mathrm{C}$} & Palm oil & 0.9693 & 0.0004 & 0.9555 & 0.0008 \\
\hline & & Lard & 0.9941 & 0.0000 & 0.9724 & 0.0003 \\
\hline & & Soybean oil & 0.9815 & 0.0001 & 0.9044 & 0.0035 \\
\hline & \multirow{3}{*}{$90^{\circ} \mathrm{C}$} & Palm oil & 0.9522 & 0.0009 & 0.9300 & 0.0019 \\
\hline & & Lard & 0.9907 & 0.0000 & 0.9888 & 0.0000 \\
\hline & & Soybean oil & 0.9980 & 0.0000 & 0.9827 & 0.0001 \\
\hline
\end{tabular}

odorants and the five aldehydes. However, the correlation between $\mathrm{CV}$ and the concentration of the five aldehydes was lower than that observed with POV. These findings suggest that the concentration of five aldehydes can be best estimated by using measurements of POV.

The AV method is used as an analytical measure in various countries because of its superior convenience and speed. Although AV increases with increasing extent of degradation, the mechanism of acid generation varies depending on the preservation conditions; thus, it is difficult to accurately assess the extent of degradation based on $\mathrm{AV}$ alone. In addition, $\mathrm{AV}$ is sometimes abnormally large, as some types of edible oil generate free fatty acids (FFA) by the hydrolysis of fatty-acid esters under the alkaline conditions used for the standard measurement ${ }^{11}$. Moreover, as shown in Table 2, the correlation between the concentration of the five aldehydes and AV was not significant. These findings suggest that AV is not suitable as an indicator of the safety of edible oils during the early stages of the oxidation process, from the perspective of human health.

$\mathrm{CV}$ reflects the amount of carbonyl compounds, in- cluding secondary products generated during the oxidation of oils; this value is therefore correlated with off-flavors. Although there are many methods for the determination of $\mathrm{CV}$, there is no one universally accepted technique. The phenylhydrazine method is simple and is the most commonly performed test; we therefore chose the phenylhydrazine method in this study. However, the values obtained with the phenylhydrazine method tend to be affected by the purity of the solvent used. In addition, this technique requires strict control of the reaction time, as no stopping solutions are available. For these reasons, $\mathrm{CV}$ is expected to be a less reproducible indicator for quality control than either AV or POV.

POV showed significant correlations with the concentration of the five aldehydes and the total concentration of odorants (Table 2). In addition, unlike AV, POV can be used to assess changes in the extent of oxidation during the early stages of oil oxidation, because the primary product of this process is measured. Moreover, it is relatively easy to measure POV compared with the direct measurement of odorants in oils. However, POV eventually decreased as oxidation progressed. Thus, as the quality of foods starts to decrease with the genera- 
Table 3. Linear relationship of POV with the concentration of five unsaturated aldehydes formed during heat storage and the calculated POV corresponding to the maximum tolerated dosed

\begin{tabular}{|c|c|c|c|c|}
\hline \multirow[t]{2}{*}{ Temperature } & \multirow[t]{2}{*}{ Sample } & \multicolumn{2}{|c|}{ Relationship* } & \multirow{2}{*}{$\begin{array}{c}\begin{array}{c}\text { Calculated POV } \\
(\mathrm{meq} / \mathrm{kg})\end{array} \\
296 \mathrm{ppm}^{* *}\end{array}$} \\
\hline & & Slope & $y$ intercept & \\
\hline \multirow{3}{*}{$50^{\circ} \mathrm{C}$} & Palm oil & 0.2545 & -7.1 & 68.3 \\
\hline & Lard & 0.1627 & 22.7 & 70.9 \\
\hline & Soybean oil & 0.1661 & 1.4 & 50.5 \\
\hline \multirow{3}{*}{$70^{\circ} \mathrm{C}$} & Palm oil & 0.1926 & -2.0 & 55.1 \\
\hline & Lard & 0.1533 & 9.1 & 54.4 \\
\hline & Soybean oil & 0.1596 & 9.4 & 56.8 \\
\hline \multirow{3}{*}{$90^{\circ} \mathrm{C}$} & Palm oil & 0.2062 & -3.1 & 57.9 \\
\hline & Lard & 0.1562 & 8.6 & 54.9 \\
\hline & Soybean oil & 0.1334 & 3.3 & 42.8 \\
\hline
\end{tabular}

$* x=$ concentration of unsaturated aldehydes (ppm); $y=\mathrm{POV}$ (meq/kg)

** The maximum tolerated dose derived from the lowest NOAEL.

tion of toxic aldehydes from the primary products of oil oxidation, and as the AV increases as oil oxidation progresses, it is desirable to adopt both $\mathrm{AV}$ and $\mathrm{POV}$ measures in the quality control of foods with high oil contents.

Although the standard POV (30 meq/kg) in Japan was introduced as a result of a previous food-poisoning event $^{2)}$, there is little scientific evidence to support its validity. We found that the five unsaturated aldehydes in oxidized oils are highly cytotoxic, in agreement with previous findings ${ }^{12}$. Based on their chemical structures, these aldehydes may show similar extents of toxicity. In fact, $t$-2-decenal, $t, t$-2,4-decadienal and $t$-2-undecenal have been reported to be harmful to the skin, while $t, t$ 2,4-decadienal shows mucosal toxicity ${ }^{13)}$. In addition, POV was more highly correlated with the total concentration of unsaturated aldehydes than with that of 14 odorants (Table 2). These observations support the value of establishing a standard POV for use in the quality control of foods containing high oil levels from the perspective of human health.

In Japan, the actual average daily oil intake is 57.4 $\mathrm{g}^{14)}$. Thus, assuming that the average Japanese body weight is $50 \mathrm{~kg}$, the average intake of oil is $1.148 \mathrm{~g} / \mathrm{kg} /$ day. According to the results of a sub-chronic toxicity test in rats reported by the National Toxicology Program ${ }^{13)}$, the no observed adverse effect level (NOAEL) of $t, t$-2,4-decadienal was $100 \mathrm{mg} / \mathrm{kg} /$ day and the acceptable daily intake (ADI) was $1 \mathrm{mg} / \mathrm{kg} /$ day. Therefore, the maximum concentration at which the $t, t$ 2,4-decadienal content in the oils ingested daily would not exceed the ADI is about $870 \mathrm{ppm}\left(1 \times 10^{-3} / 1.148\right)$. However, the data summarized by the World Health Organization ${ }^{15)}$ indicated a NOAEL of $t, t$-2,4-decadienal of $34 \mathrm{mg} / \mathrm{kg} /$ day and a corresponding maximum concentration of $296 \mathrm{ppm}\left(0.34 \times 10^{-3} / 1.148\right)$.

The maximum allowable concentration of $t, t-2,4$ decadienal, which showed the highest cytotoxicity among the compounds tested, should also be applicable to the total concentration of the five unsaturated alde- hydes, because $t, t$-2,4-decadienal was their major component (data not shown) and the cytotoxicity of the five aldehydes was higher than that of the other odorants. The calculated POVs, which correspond to $296 \mathrm{ppm}$, are shown in Table 3.

Based on such values, it might be possible to set appropriate POV standards for oils in foods for consumer's safety and information.

Further, it might be useful to set POV standards for oils in foods, because the reasons for measuring POV and $\mathrm{AV}$ are different. $\mathrm{AV}$ is an index to measure the amount of FFA mainly formed by the hydrolysis of oils in foods. On the other hand, POV is not only an index to quantify the amount of hydroperoxide in the initial stage of oxidation of oils, but also a useful indicator of toxic secondary products, such as the five aldehydes shown here. In conclusion, from the viewpoint of food safety, we have confirmed that POV is a useful standard for the quality control of products, such as instant noodles, which contain high concentrations of oils.

\section{Acknowledgments}

The authors thank Mr. Keiji Sugino for performing the tocopherol analyses, Mr. Katsuhiro Date for providing the spectral data, Ms. Kyoko Echigo for performing the titration studies, and Dr. Yoichi Nobuhara, Dr. Yukio Yoneda and Dr. Tadashi Okumura for general advice.

\section{References}

1) Chan, H. W-S., "Autoxidation of Unsaturated Fatty Acids”, Chan, H. W.-S. ed., London, Academic Press, 1987, p. $1-16$.

2) Inagaki, N., Food-poisoning caused by instant noodle. Shokuhin Eisei Kenkyu (Food Sanitation Research), 16, 370-379 (1996).

3) Vaisey-Genser, M., Malcolmson, L. J., Ryland, D., Przybylski, R., Eskin, N. A. M., Armstrong, L., Consumer acceptance of canola oils during temperatureaccelerated storage. Food Qual. Preference, 5, 237-243 (1994). 
4) Mahungu, S. M., Hansen, S. L., Artz, W. E., Identification and quantitation of volatile compounds in two heated model compounds, trilinolein and linoleic acid esterified propoxylated glycerol. J. Agric. Food Chem., 47, 690-694 (1999).

5) Endo, Y., Li, C.M., Tagiri-Endo, M., Fujimoto, K., A modified methods for the estimation of total carbonyl compounds in heated and frying oils using 2-propanol as a solvent. J. Am. Oil Chem. Soc., 78, 1021-1024 (2001).

6) Cert, A., Moreda, W., Pérez-Camino, M. C., Chromatographic analysis of minor constituents in vegetable oils. J. Chromatogr., 881, 131-148 (2000).

7) Kimoto, Y., Tanji, Y., Taguchi, T., Sugimoto, T., Watanabe, T., Tsukamoto, F., Kim, S., Yoneda, K., Takamura, Y., Izukura, M., Shiba, E., Takai, S., Antitumor effect of medium-chain triglyceride and its influence on the selfdefense system of the body. Cancer Detect. Prev., 22, 219-224 (1998).

8) Ekwall, B., Johanson, A., Preliminary studies on the validity of in vitro measurement of drug toxicity using HeLa cells. I. Comparative in vitro cytotoxicity of 27 drugs. Toxicol. Lett. 5, 299-307 (1980).

9) Ishiyama, M., Shiga, M., Sakamoto, K., Mizoguchi M., He, P., A new sulfonated tetrazolium salt that produces a highly water-soluble formazan dye. Chem. Pharm. Bull., 41, 1118-1122 (1993).
10) Nappez, C., Battu, S., Beneytout, J. L., trans,trans-2,4Decadienal: cytotoxicity and effect on glutathione level in human erythroleukemia (HEL) cells. Cancer Lett., 99, 115-119 (1996).

11) Kawaguchi, Y., Morita, T., Yanae, K., Setoguchi, Y., Kato, M., Method of acid value determination for oils containing alkali-labile esters. J. Oleo Sci., 53, 329-336 (2004).

12) Müller, K., Hardwick, S. J., Marchant, C. E., Law, N. S., Waeg, G., Esterbauer, H., Carpenter, K. L. H., Mitchinson, M. J., Cytotoxic and chemotactic potencies of several aldehydic components of oxidised low density lipoprotein for human monocyte-macrophages. FEBS Lett., 388, 165-168 (1996).

13) NTP Studies on 2,4-Decadienal, Study No. C93022B, National Toxicology Program at the National Institutes of Health's National Institute of Environmental Health Sciences located in Research Triangle Park, NC.

14) Health and nourishment information society, "State of National Nourishment (The Result of National Nourishment Investigation in Japan by Ministry of Health, Labour and Welfare, 2002)", Tokyo, Dai-Ichi Shuppan, 2004.

15) Damaske, D. R., Mechler, F. J., Beliles, R. P., Liverman, J. L., Report on 2,4-decadienal. Unpublished report. Submitted to WHO by Flavor and Extract Manufacturers Association of the United States (1980). 